\title{
KINETICS OF SELECTIVE CATALYTIC REDUCTION OF NITRIC OXIDE OVER PT-CU-ZSM5 CATALYST
}

\author{
ISMAIl MOHD SAAID*, ABdul RaHMan MOHAMEd AND SUbHaSH BHATIA** \\ * Mechanical Engineering Program, Universiti Teknologi Petronas, Bandar Sri Iskandar, \\ 31750 Tronoh, Perak, MALAYSIA \\ **School of Chemical Engineering, Engineering Campus, Universiti Sains Malaysia, 14300 \\ Nibong Tebal, Seberang Perai Selatan, P. Pinang, MALAYSIA \\ E-mail: chbhatia@eng.usm.my
}

\begin{abstract}
Kinetics for the selective catalytic reduction (SCR) of nitric oxide (NO) using $\mathrm{i}-\mathrm{C}_{4} \mathrm{H}_{10}$ as the reducing agent over Pt-Cu-ZSM5 has been investigated in the temperature range of $200{ }^{\circ} \mathrm{C}-450{ }^{\circ} \mathrm{C}$. Langmuir-Hinshelwood-Hougen-Watson model was proposed for kinetics of the reaction and reaction parameters were evaluated. The heat of adsorption of NO was found to be considerably high, attributed to strong covalent bond between $\mathrm{NO}$ gas molecules and metal active sites. Using reaction parameters obtained from the experiment, the heterogeneous model could form a good correlation between experimental and simulated values of NO reduction.
\end{abstract}

Key Words: Reaction kinetics, Selective catalytic reduction, NO reduction, Bimetallic catalyst, H-ZSM-5 zeolite.

\section{INTRODUCTION}

For the past decade, the intensive research on the methods for the decomposition of toxic and harmful species in the diesel exhaust gas have been reported [1]. The diesel engine is more economical and produces less concentration of hydrocarbons and carbon monoxide compare to other internal-combustion engines. However, the diesel exhaust emissions contain appreciable concentration of NOx, and its removal become more stringent together with those of hydrocarbons and carbon monoxide under the international environment regulations. The reduction of NOx emissions from diesel engines is done either by the modification of engine or reducing the emissions by addition of a reducing agent into the exhaust gas.

Selective catalytic reduction using a hydrocarbon as a reducing agent (HC-SCR) has been widely proposed as one of the promising techniques to reduce the emission of nitric oxide (NO) from diesel engine exhaust $[1,2]$. The technique eliminates the use of ammonia and its associated risk of storage commonly used in the selective catalytic reduction process at nitric acid or power plants. Besides, the availability of unburned hydrocarbons in diesel exhaust can be utilised as a reducing agent. Many types of catalysts especially those supported on ZSM-5 zeolite such as Cu-ZSM5, Co-ZSM5, Ni-ZSM5 and Fe-ZSM5 have been proposed ${ }^{[2,3]}$. One of the major drawbacks is that these catalysts operate in a narrow temperature window for optimum reduction of NO. Recently we reported that platinum and copper co-loaded 
on ZSM-5 zeolite could considerably widen the temperature window for optimum reduction of NO [4].

In the present study reaction kinetics of the HC-SCR process of NO using i-butane as the reducing agent over Pt-Cu-ZSM5 catalyst is reported. The reaction parameters were obtained from the proposed heterogeneous model based on LangmuirHinshelwood-Hougen-Watson (LHHW) mechanism. The reaction parameters obtained were used to simulate the reduction of $\mathrm{NO}$ in the packed bed reactor and compared with the experimental data obtained using the bimetallic Pt-Cu-ZSM5 catalyst.

\section{EXPERIMENTAL}

Samples of bimetallic catalysts, Pt-Cu-ZSM5 were prepared by successive wet ion exchange process using $0.01 \mathrm{M}$ copper nitrate and $0.0003 \mathrm{M}$ chloroplatinic acid as chemical precursors for copper and platinum respectively ${ }^{[4]}$. The H-ZSM5 zeolite support (Si/Al ratio 90) was supplied by Süd - Chemie AG, Munich. In essence, 10 g. of H-ZSM5 zeolite and $100 \mathrm{ml}$. of respective metal solutions were used during wet ion exchange process. The wet ion exchange process was carried out in six 24-hour stages with vacuum filtration in between stages before drying overnight in static air at $110^{\circ} \mathrm{C}$. The bimetallic catalyst samples were calcined in static air by increasing the temperature step-wise at $10{ }^{\circ} \mathrm{C} / \mathrm{min}$ and held at $500{ }^{\circ} \mathrm{C}$ for 1 hour. For comparison purposes, monometallic catalysts, Pt-ZSM5 and Cu-ZSM5 were also prepared using wet ion exchange process. Samples were analysed in nitrogen adsorption isotherm (Autosorb 1C) and electron dispersive X-ray technique (Editor Camscan) to examine their physical properties and chemical composition respectively as presented in Table 1. The powder form of all samples was made into granular form by pressing under 35 tons, meshed into 250 - $355 \mu \mathrm{m}$ size before catalytic activity measurements.

Steady state catalytic activity measurements were carried out in a microcatalytic reactor (stainless steel tube $6 \mathrm{~mm}$ diameter and length $300 \mathrm{~mm}$ ), horizontally placed in a mini tubular furnace (Lindberg Blue M). In-situ pre-treatment was carried out in flowing $\mathrm{H}_{2}(100 \mathrm{ml} / \mathrm{min})$ at $450{ }^{\circ} \mathrm{C}$ for 4 hours for reduction of metal

$$
\% \text { NO Reduction }=\left[\frac{\mathrm{C}_{\text {in }}-\mathrm{C}_{\text {out }}}{\mathrm{C}_{\text {in }}}\right] \times 100
$$

oxides to metal form. Type $\mathrm{K}$ thermocouple connected to digital scanning thermometer (Cole Palmer model 92000-05) measured the catalyst bed temperature. Mass flow control system (MKS type 1179A controllers connected to MKS type 247 4-channel control box) was used to prepare a feed gas mixture of $1000 \mathrm{ppm}$ NO, $1500 \mathrm{ppm}$ i- $\mathrm{C}_{4} \mathrm{H}_{10}, 3 \% \mathrm{O}_{2}$, and balanced by $\mathrm{N}_{2}$. Online gas chromatograph (Shimadzu 8A) equipped with Porapak Q column (80/100 mesh size) and Molecular Sieve $5 \mathrm{~A}$ was used for analysis of gas $\left(\mathrm{N}_{2}, \mathrm{O}_{2}, \mathrm{i}-\mathrm{C}_{4} \mathrm{H}_{10}, \mathrm{~N}_{2} \mathrm{O}\right.$ and $\left.\mathrm{CO}_{2}\right)$ at the inlet and outlet of the reactor. ENERAC 2000E emission gas analyzer was used to measure online concentrations of NO in ppm at the inlet and outlet stream. Percentage of NO reduction was calculated from the difference in the inlet and outlet concentration of $\mathrm{NO}\left(\mathrm{C}_{\mathrm{in}}\right.$ and $\left.\mathrm{C}_{\text {out }}\right)$ as expressed in Eq. (1). 


\section{RESULTS AND DISCUSSION}

\subsection{Temperature window Reaction.}

Figure 1 shows temperature profiles of bimetallic catalysts as compared with monometallic Pt-ZSM5 and Cu-ZSM5 for the reduction of NO. Pt-ZSM5 was clearly active in the low temperature region with maximum NO reduction of $70 \%$ at $250{ }^{\circ} \mathrm{C}$. Further increase in the temperature caused immediate drop in the NO reduction, which became negligible above $500{ }^{\circ} \mathrm{C}$. On the other hand, Cu-ZSM5 had negligible NO reduction below $250{ }^{\circ} \mathrm{C}$ before a drastic increase to almost $100 \%$ reduction at $350{ }^{\circ} \mathrm{C}$. The NO reduction remained relatively high even though there was a slight decline as temperatures were further increased. These results on $\mathrm{Cu}-\mathrm{ZSM} 5$ and $\mathrm{Pt}$ ZSM5 agreed quite well with reported results ${ }^{[5,6,7]}$. Temperature profiles of bimetallic catalysts (samples 1 and 2) showed synergistic effects of copper and platinum. In both samples, the range of temperature for optimum NO reduction was expanded. Pt-Cu-ZSM5 (I) offered the largest operating window than any other samples where more than $50 \% \mathrm{NO}$ could be reduced over $250{ }^{\circ} \mathrm{C}-500{ }^{\circ} \mathrm{C}$ region. Regardless of the type of catalysts, their temperature profiles illustrated the general trend of catalytic activity for the reduction of NO. The declining NO reduction at high temperature was primarily attributed to excessive oxidation of hydrocarbon outside zeolite pores. Besides, the relatively high temperature environment would possibly inhibit adsorption of intermediate species on the catalyst surface for the SCR process.

\subsection{Mechanism and Kinetic Modeling}

The mechanism of catalytic reduction of NO is quite complicated because it composed of multiple reaction steps and formation of various intermediate species ${ }^{[8,9]}$. It was reported that there were a number of active sites for each reaction step in the HC-SCR of $\mathrm{NO}^{[1]}$. There were sites for the oxidation of $\mathrm{NO}$ to $\mathrm{NO}_{2}$, sites for the coupling of nitrogen-containing molecules, sites for the activation of hydrocarbon and sites for the formation of carbon oxides [1]. Moreover, the same site might be involved in more than one reaction step [1]. This was supported by a FourierTransformed-Infrared study indicating that at least two active sites were involved in the $\mathrm{NO}$ reduction process ${ }^{[9]}$. One site was associated with the $\mathrm{Al}$ site of the zeolite support and the other site was attributed to metal cations such as $\mathrm{Cu}^{2+}$ exchanged into the zeolite structure. For simplification of the reaction mechanism, it was assumed that the catalyst contained only one type of active site on which adsorption, surface reaction and desorption took place [1,9]. These adsorption, surface reaction and desorption steps are represented as follows.

\section{Adsorption.}

$\begin{array}{ccc}\mathrm{O}_{2}+2 \mathrm{~S} & \leftrightarrows & 2 \mathrm{O} \cdot \mathrm{S} \\ \mathrm{NO}+\mathrm{S} & \leftrightarrows & \mathrm{NO} \cdot \mathrm{S} \\ \mathrm{C}_{4} \mathrm{H}_{10}+\mathrm{S} & \leftrightarrows & \mathrm{C}_{4} \mathrm{H}_{10} \cdot \mathrm{S}\end{array}$




\section{Surface reaction.}

$\mathrm{C}_{4} \mathrm{H}_{10} \cdot \mathrm{S}+11 \mathrm{O} \cdot \mathrm{S}+2 \mathrm{NO} \cdot \mathrm{S} \leftrightarrows \mathrm{N}_{2} \cdot \mathrm{S}+4 \mathrm{CO}_{2} \cdot \mathrm{S}+5 \mathrm{H}_{2} \mathrm{O} \cdot \mathrm{S}+4 \mathrm{~S}$

Desorption.

$\begin{array}{lll}\mathrm{N}_{2} \cdot \mathrm{S} & \leftrightarrows & \mathrm{N}_{2}+\mathrm{S} \\ \mathrm{CO}_{2} \cdot \mathrm{S} & \leftrightarrows & \mathrm{CO}_{2}+\mathrm{S} \\ \mathrm{H}_{2} \mathrm{O} \cdot \mathrm{S} & \leftrightarrows & \mathrm{H}_{2} \mathrm{O}+\mathrm{S}\end{array}$

These reaction steps could be generalized as Eq. (9).

$2 \mathrm{NO}+\mathrm{C}_{4} \mathrm{H}_{10}+5.5 \mathrm{O}_{2} \rightarrow \mathrm{N}_{2}+4 \mathrm{CO}_{2}+5 \mathrm{H}_{2} \mathrm{O}$.

The surface reaction expressed by Eq. (5) is where adsorbed molecules of i-butane, oxygen and nitrogen oxide react on the catalyst surface. Oxygen concentration is much higher compared to NO and i-butane, therefore the rate of reaction will be independent of oxygen concentration. Assuming adsorptions of NO and hydrocarbon control the reaction, the rate of reaction $\left(-r^{\prime}{ }_{\mathrm{NO}}, \mathrm{mol} / \mathrm{m}^{3}\right.$.s.gcat $)$ based on LHHW ${ }^{[10,11]}$ is expressed as:

$$
\left(-r_{\mathrm{NO}}\right)^{\prime}=\frac{k K_{1} K_{2} \mathrm{C}_{\mathrm{NO}} \mathrm{C}_{\mathrm{CH}}}{\left(1+K_{1} \mathrm{C}_{\mathrm{NO}}+K_{2} \mathrm{C}_{\mathrm{CH}}\right)}
$$

where, $C_{\mathrm{NO}}$ and $C_{\mathrm{CH}}$ are the concentrations of $\mathrm{NO}(\mathrm{ppm})$ and $\mathrm{i}-\mathrm{C}_{4} \mathrm{H}_{10}$ (ppm) respectively, $K_{1}\left(\mathrm{~m}^{3} / \mathrm{mol}\right)$ and $K_{2}\left(\mathrm{~m}^{3} / \mathrm{mol}\right)$ are the adsorption equilibrium constants for $\mathrm{NO}$ and $\mathrm{i}-\mathrm{C}_{4} \mathrm{H}_{10}$ respectively and $k_{\mathrm{s}}\left(\mathrm{m}^{3} /\right.$ mol.s.gcat. $)$ is the apparent reaction rate constant.

For estimating the rate of reaction from experiments, concentrations of NO was measured at different space time in the temperature range of $250{ }^{\circ} \mathrm{C}-400{ }^{\circ} \mathrm{C}$ as shown in Figure 2. The curves were fitted with suitable polynomials obtained from the Microsoft Excel program to represent the trend of the concentration profile. The second order polynomials presented in Table 2 satisfactorily fitted the concentration profile at each temperature. Nevertheless, a few data points were omitted from the polynomials and initial concentrations $\left(C_{\mathrm{NO}}\right)_{\mathrm{o}}$ were slightly different as per polynomial data fitting. The rate of reaction, $\left(-r_{\text {NO }}^{\prime}\right)$, in Eq. (10) was calculated from the differential of $C_{\mathrm{NO}}$ polynomial, $\left(-\mathrm{dC}_{\mathrm{NO}} / \mathrm{d} \tau\right)$ divided by the weight of catalyst at respective space time $(\tau)$. Based on the general reaction Eq. (9), the concentration of hydrocarbon, $C_{\mathrm{CH}}$, could be stochiometrically expressed in terms of $C_{\mathrm{NO}}$ as in Eq. (11).

Both rates of reaction obtained from the experiment at each temperature and concentrations of NO were used as inputs for a non-linear regression analysis to obtain estimated values of $k_{\mathrm{s}}, K_{1}$ and $K_{2}{ }^{[11,12]}$. These values are summarized in Table 3. It can be seen that the adsorption equilibrium constant for $\mathrm{NO}\left(K_{1}\right)$ is remarkably larger than that of $\mathrm{i}-\mathrm{C}_{4} \mathrm{H}_{10}\left(K_{2}\right)$. This further suggests that the adsorption of NO could be rate controlling. It was also reported that the adsorption of the hydrocarbon (1600 ppm) and water vapor (2\%) did not appear in the denominator of the heterogeneous rate model using Co-Ferrierite catalyst [10]. The study indicated that the adsorption 
effect of either methane or water rapidly decreased at increasing reaction temperatures [10]. Shen and Kawi ${ }^{[13]}$ found negligible effect of propylene adsorption on the catalytic reduction of NO using Pt-MCM-41 catalyst. The study suggested that most of the active sites of the catalyst were blocked by NO species even at low temperatures of below $150{ }^{\circ} \mathrm{C}$ [13].

The activation energy of the reaction was estimated from the slope of the plot of apparent rate constant, $k_{s}$ against the reciprocal of reaction temperature, 1/T shown in Figure 3. From the slope of the curve, the activation energy was found to be $58 \pm 1$ $\mathrm{kJ} / \mathrm{mol}$. This value of activation energy was also lower than reported values of 62 $\mathrm{kJ} / \mathrm{mol}$ (CoOx-alumina) ${ }^{[9]}, 92 \mathrm{~kJ} / \mathrm{mol}$ (Co-Ferrierites) [10], and $123 \mathrm{~kJ} / \mathrm{mol}(\mathrm{Cu}-$ ZSM5) ${ }^{[14]}$ due to different types of catalysts. The bimetallic catalyst in the present study was active in the low temperature range of $250{ }^{\circ} \mathrm{C}-450{ }^{\circ} \mathrm{C}$ that favored catalytic reduction of NO over oxidation of the hydrocarbon.

The heat of adsorption was estimated from the slope of the plot of $K_{1}$ against the reciprocal of temperature shown in Figure 4. The apparent adsorption equilibrium constant is expressed as in Eq. (12) [15].

$$
K_{1}=\mathrm{A} \exp \left(\frac{-\Delta \mathrm{H}_{\mathrm{ads}}}{\mathrm{RT}}\right)
$$

where, $\mathrm{A}$ is the pre-exponential factor $\left(e^{\Delta^{\mathrm{s}} / \mathrm{R}}\right),\left(-\Delta \mathrm{H}_{\mathrm{ads}}\right)$ is the heat of adsorption, $\mathrm{R}$ is the gas constant $(8.314 \mathrm{~J} / \mathrm{mol}$. $\mathrm{K})$ and $\mathrm{T}$ is the temperature $(\mathrm{K})$. The heat of adsorption was found to be $-62 \mathrm{~kJ} / \mathrm{mol}$, a negative value since adsorption is an exothermic process. The heat adsorption value was considerably high due to possible covalent bonds between NO gas molecules and metal active sites [16]. In fact, heat of adsorption of NO on other transition metals such as Ni and Pd were as high as 105 $-130 \mathrm{~kJ} / \mathrm{mol}$ [16]. The heat of adsorption data in the catalytic reduction of NO were not reported in the literature, therefore it was difficult to compare the value obtained in the present study from the reported value. It was suggested that the LangmuirHinshelwood-Hougen-Watson (LHHW) rate expression was more suitable for catalyzed reactions. Its denominator took into account the reduction in rate due to adsorption phenomena [15].

\subsection{Simulation of rate law model for prediction of NO reduction}

The proposed heterogeneous model in Eq. (10) took into account the adsorption effects of NO and hydrocarbon. It was of interest as well to evaluate the pore diffusion effect on the reaction rate because the catalyst was in the particle form. Results from two experimental runs at 20,000 $\mathrm{hr}^{-1}$ with Pt-Cu-ZSM5(I) catalyst conducted at two different particle sizes of $0.80-1.00 \mathrm{~mm}$ and $0.25-0.35 \mathrm{~mm}$ are shown in Figure 5. It shows that both particle sizes gave almost same values of NO reduction (i.e. maximum NO reduction of about $80 \%$ at $350{ }^{\circ} \mathrm{C}$ ). This suggests that particle diffusional effect could be neglected in the kinetic model. The absence of mass transfer effects were also checked using Weisz-Parter criterion ${ }^{[11]}$. It was found that internal pore diffusion had negligible effect on the rate of reaction ${ }^{[17]}$. Therefore, the rate model represented by Eq. (10) is free from mass transfer effects and could be used for prediction of NO reduction in a packed bed catalytic reactor.

For simulation of fractional values of NO reduction, integration was performed on the expression for contact time ( $\tau$, second) for a packed bed reactor, Eq. (13) and is simplified as Eq. (14). 


$$
\begin{gathered}
\tau=\int_{0}^{\left(\mathrm{X}_{\mathrm{No}}\right)_{r} \frac{\mathrm{dX}_{\mathrm{NO}}}{\left[-r^{\prime}{ }_{\mathrm{NO}}\right]}} \\
\tau=\frac{6.5}{k_{s} \mathrm{C}_{\mathrm{NO}_{\mathrm{o}}}}\left(\frac{1}{k_{s} \mathrm{C}_{\mathrm{NO}_{\mathrm{o}}}\left(9.75-\mathrm{X}_{\mathrm{NOf}}\right)} \ln \left(\frac{9.75-\mathrm{X}_{\mathrm{NOf}}}{9.75\left(1-\mathrm{X}_{\mathrm{NOf}}\right)}\right)+\mathrm{K}_{1} \ln \left(\frac{1}{9.75-\mathrm{X}_{\mathrm{NOf}}}\right)\right)
\end{gathered}
$$

where, $\left(\mathrm{X}_{\mathrm{NO}}\right)_{\mathrm{f}}$ represents the final fractional reduction of NO. The integration was performed by eliminating the hydrocarbon adsorption effect as suggested by negligible $K_{2}$ values. The value of $\tau$ was calculated by using a series of different $\left(\mathrm{X}_{\mathrm{NO}}\right)_{\mathrm{f}}$ values until it matched with that of the experimental values. The simulated values of $\mathrm{NO}$ reduction, $\left(\mathrm{X}_{\mathrm{NO}}\right)_{\text {cal }}$. were compared with experimental values, $\left(\mathrm{X}_{\mathrm{NO}}\right)_{\text {exp }}$, as parity plots shown in Figure 6 . Figure 6 clearly shows that simulated values do not deviate significantly from the experimental values. However, a few simulated values at $400{ }^{\circ} \mathrm{C}$ and $450{ }^{\circ} \mathrm{C}$ were significantly higher than experimental values. It probably suggested a change in the reaction mechanism since the mean errors were in large interval (i.e. $21.6 \pm 18.5,24.0 \pm 20.4$ at 400 and $450{ }^{\circ} \mathrm{C}$ respectively) at 95 percent level of confidence [17].

\section{CONCLUSIONS}

The kinetics parameters were evaluated based on reaction mechanism in the NO reduction process involving hydrocarbon. A heterogeneous model was based on the Langmuir-Hinshelwood-Hougen-Watson (LHHW) reaction mechanism between NO and hydrocarbon on the catalyst surface. The activation energy of $58.1 \pm 1 \mathrm{~kJ} / \mathrm{mol}$ reflected the low range of temperatures $\left(250{ }^{\circ} \mathrm{C}-450{ }^{\circ} \mathrm{C}\right)$ for the optimum reduction of NO. The reaction parameters for NO reduction obtained from the model were used to predict the reduction of $\mathrm{NO}$ over wide range of temperature $\left(250{ }^{\circ} \mathrm{C}-450\right.$ ${ }^{\circ} \mathrm{C}$ ) and gas hourly space velocity of $10,000-100,000 \mathrm{hr}^{-1}$. The predicted values of NO reduction from the model did correlate quite well with experimental values since the model took the adsorption effect of NO into account in addition to concentrations of NO and i-butane in the rate expression. It showed that the NO adsorption had a major influence on the rate of reaction with $61.8 \pm \mathrm{kJ} / \mathrm{mol}$ of heat of adsorption reflecting strong interaction between NO molecules and active metal species on the catalyst surface. The proposed model was tested and validated on the basis of experimental data and statistical analysis, which was applicable within a certain range of conditions studied experimentally. The proposed model should not be extrapolated beyond its range of study.

\section{ACKNOWLEDGEMENTS}

The authors acknowledge the short term research grant provided by Universiti Sains Malaysia, Penang (FPP 2001/040) that has enabled the production of this article.

\section{REFERENCES}

[1] M. Shelef, "Selective Catalytic Reduction of NOx with N-Free Reductants", Chem. Rev., Vol. 95, pp. 209-225, 1995 
[2] P.J Ramirez, G. Cortes, J.M.I. Gomez, F. Kapteijn, J.A. Moulijn, and S.M.C. Lecea, "Reduction of NO by propene over Pt, Pd, and Rh-based ZSM-5 under lean burn conditions", React. Kinet. Catal. Lett., Vol. 69, No. 2, pp. 385-392, 2000.

[3] I. M., Saaid, A.R. Mohamed, and S. Bhatia, "Comparative Study of $\mathrm{Cu}-$ ZSM5 and Fe-ZSM5 in the SCR of NOx with i- $\mathrm{C}_{4} \mathrm{H}_{10}$ ", React. Kinet. Catal. Lett., Vol.75. No. 2 pp. 359-365, 2002.

[4] I. M., Saaid, A.R. Mohamed, and S. Bhatia, "Activity and Characterization of Bimetallic ZSM-5 for the Selective Catalytic Reduction of NOx", Journal of Molecular Catalysis A: Chemical, Vol. 189, pp. 241-250, 2002.

[5] G. Cortes, J.M.I. Ramirez, J.P. Gomez, F. Kapteijn, J.A. Moulijn and S.M.C. Lecea, "Effect of the support in de-NOx HC-SCR over transition metal catalysts", React. Kinet. Catal. Lett., Vol. 70, No. 2, pp. 199-206, 2000.

[6] G. Cortes, J.M.I. Gomez, A.L. Solano, and S.M.C. Lecea, "Low temperature SCR of NOx with $\mathrm{C}_{3} \mathrm{H}_{6}$ under lean-burn conditions on activated carbonsupported platinum”, App. Catal. B: Env.,Vol. 25, pp. 39-48, 2000.

[7] C.E Quincoces, A. Kikot, E.I Basaldella, and M.G. Gonzalez, "Effect of hydrothermal treatment on Cu-ZSM5 catalyst in the selective reduction of NO”, Ind. Eng. Chem. Res., Vol. 38, pp. 4236-4240, 1999.

[8] P. Carniti, A. Gervasini, V. H. Modica and N. Ravasio, "Selective Catalytic Reduction of NO with ethylene over a series of copper catalysts on amorphous silicas" Appl. Catal. B: Env., Vol 28, pp. 175-185, 2000.

[9] T. Maunula, J. Ahola and H. Hamada, "Reaction mechanism and kinetics of NOx reduction by propene on CoOx/alumina catalysts in lean conditions", Appl. Catal. B: Env. Vol. 26, pp. 173-192, 2000.

[10] Y. Li and J.N. Armor, "Selective reduction of NOx by methane on CoFerrierites", Journal of Catalysis, Vol. 150, No. 2, pp. 376-387, 1994.

[11] H.S. Fogler, Elements of Chemical Reaction Engineering, Prentice Hall, $3^{\text {rd }}$ edn. New Jersey, 1999.

[12] W.H. Press, B.D. Flannery, S.A. Teukolsky and W.T. Vetteoling, Numerical Recipes, Cambridge Univ. Press., Cambridge, 1986.

[13] S.C. Shen and S. Kawi, "Kinetics studies of selective catalytic reduction of NO by propylene on Pt-MCM-41 catalyst", Catal. Today. Vol. 68, pp. 245-254, 2001.

[14] V. Tomasic, Z. Gomzi, and S. Zrncevic, "Catalytic reduction of NOx over CuZSM5 catalyst”, Appl. Catal. B: Env. Vol. 18, No. 3-4, pp. 233-240, 1998.

[15] C.N. Satterfield, Heterogeneous Catalysis in Industrial Practice, $2^{\text {nd }}$ edn., Mc. Graw Hill Inc., Singapore, 1993.

[16] J.M.Thomas, and W.J. Thomas, Principles and Practice of Heterogeneous Catalysis, VCH Verlagsgesellschaft mbH, Weinheim (Germany), 1997.

[17] I.M Saaid, "Develeopment of zeolite supported catalyst for the reduction of NOx in diesel engine emissions", Ph.D Thesis, P.Pinang, Univ. Sains Malaysia, 2002 .

\section{BIOGRAPHIES}

Dr. Ismail Mohd Saaid: He received B.Sc in Petroleum Engineering from the University of Missouri-Rolla in 1993, MSc. in Environmental Technology from the University of Manchester Institute of Science and Technology in 1998 and Ph.D in Chemical Engineering from the Universiti Sains Malaysia in 2003. Prior to 
completing his MSc he worked for BP Oil Malaysia, Kuala Lumpur. His current research interest includes environmental catalysis and petroleum reservoir engineering. At present he is lecturer in Mechanical Engineering Program, Universiti Teknologi Petronas, Bandar Sri Iskandar, 31750 Tronoh, Perak, Malaysia

Assoc. Prof. Dr. Abdul Rahman Mohamad: He is the Dean, School of Chemical Engineering, Engineering Campus, Universiti Sains Malaysia. He received his B. Sc in Chemical Engineering from University of Southern California, Los Angeles in 1986. He obtained his M.Sc and P.hD also in Chemical Engineering from the University of New Hampshire, USA. His research areas are in catalysis and environmental engineering where he has published more than 70 papers in local and international journals and conferences.

Prof. Subhash Bhatia: He joined School of Chemical Engineering, Universiti Sains Malaysia in 1995. He was a Full Professor at the Department of Chemical Engineering, Indian Institute of Technology, Kanpur (India). Prof. Bhatia was a visiting faculty at the University of Queensland, Australia from 1988-89 and 19941995. His research interests are zeolite catalysis, chemical reaction engineering and environmental catalysis. He has written a book on Zeolite Catalysis that was published by CRC Press, USA and has published more than 80 papers in national and international journals. 